\title{
STEAM AS A FACTOR OF INDIVIDUAL SYSTEMS THINKING DEVELOPMENT FOR STUDENTS OF ELECTRONICS SPECIALITY
}

\author{
Yuriy Yakymenko, Yuriy Poplavko, Yuliana Lavrysh \\ National Technical University of Ukraine "Igor Sikorsky Kyiv Polytechnic Institute" \\ lavu@ukr.net
}

\begin{abstract}
The present paper addresses the issue of teaching electronics as an integrative course at university. One of the urgent demand to universities is to prepare future specialists for solving multi-tasked global problems. Therefore, educators need to employ new teaching strategies and methods. Systems thinking skills are considered as the requirement of the twenty-first century that should be developed at universities. We suggest STEAM approach as a powerful tool to foster the development of individual systems thinking skills in students of electronics speciality. In order to verify our hypothesis, we assessed students' level of system thinking skills and employed systems thinking tools development during teaching field-related and English language classes to accomplish STEAM as an approach that supports individual types of information perception through technical, creative, scientific cognitive skills. Our assumption was confirmed by the results of the post-test. Among the skills that were changed: information needs and general resources identification, feasibility and sustainability of solution assessment, root causes identification and perspectives evaluation. We also identified the most efficient practical tools and differentiated them by subjects. Due to these transformations, we are able to develop technological literacy and foster cognitive skills such as creative, critical and systems thinking for problem-solving process.
\end{abstract}

Keywords: STEAM; systems thinking skills; electronics education; individualisation; pedagogical content knowledge.

\section{Introduction}

Nowadays worldwide leading technology companies have emphasised the requirement to technology universities to equip future graduates with modern cognitive multifunctional skills. It is progressively perceived that the context of додала кому discipline knowledge but also the awareness of the key principles of information connection across multiple disciplines.This idea is supported by Connor et al. (2015) who state:

"Rather than train students to 'know' things, the goal should be to train students to 'understand' things. Understanding is about utilizing skills and competence, and contextualizing deeper knowledge. It requires action to assimilate the right concepts, to put them in situation." (p.38)

Therefore, in order to prepare engineers with a systems mindset and competencies to be effective in system engineer, technology educators have to enhance the development of systems thinking skills in engineering undergraduates (Rashmi et al,2009).

The main focus of systems thinking is on the examination of complex problems and systems taking into account interaction among their components. Such high-order thinking skill facilitates students' ability to deal with interdisciplinary real-world problems. We consider the process of electronics teaching is an excellent example and opportunity to foster the development of system thinking, in terms of STEAM approach. It is due to the fact that students are taught electronics course by learning about electronics systems that requires holistic knowledge of interconnected disciplines and systems such as electronic circuits. During the practical classes, students carry out systems assessment, verifying specific components of a system or connectors, checking and comparing properties etc.

Engineering electronics education in Ukraine has a unique structure and combines the acquisition of practical and theoretical knowledge, however, requires from the technology teachers to create a rich and flexible learning environment due to the changes in strategies, curriculum and educational contests. In order to accomplish systemic educational reforms, the technology teacher's concern is significant in determining the pedagogical content knowledge and benefits of innovative curriculum, such as STEAM-based curricular. The meaningful combination of engineering content and pedagogy produces the conversion of pure technological content into a pedagogically influential and flexible strategy that forces students' knowledge acquisition.

Since it is crucial for engineering students to acquire system thinking skills, it is logical to perform it through the complex and systemic STEAM approach with an integration of a number of disciplines: science, technology, engineering, art (language art) and math that correlate with individual types of thinking skills. Nevertheless, due to the approach complex and integrative nature, technology teachers should address a pedagogical content to be knowledgeable about the main principles and fundamentals of general pedagogy, teaching strategies for the development of practical skills and problem-solving abilities as well as class management.

The purposes of the present research are to identify the STEAM education areas that facilitate the development of individual system thinking and to present practical ways of system thinking approach

Yakymenko,Y., Poplavko, Y., \& Lavrysh, Y. (2020). STEAM as a factor of individual systems thinking development for students of electronics speciality. Advanced Education, 15, 4-11. DOI: 10.20535/2410-8286.208315 
integration into a STEAM field-related course for electrical engineers. In our paper, we attempt to find an answer to a question: how technology and language teachers can promote the development of systems thinking creating an integrative educational environment. The research hypothesis is that integration of disciplines in a STEAM course will enhance engineering students' systems thinking abilities.

\section{Theoretical background}

Although the issue of teaching systems concepts via system thinking has not been much reflected in the literature sources, due to the fact that the teaching approach "from a part to the whole" still prevails in educational settings, we have identified approaches and solutions on efficient application of system thinking approach in STEAM education disciplines. The analysis of recent research confirms that system thinking is considered to be a core concept in technology and engineering (Frank and Elata, 2005; Barlex and Steeg (2007).

Firstly, it is necessary to define the term of the system representation of an object. Foster et al. (2001) consider that the key elements of the system representation are functions, processes, structures and interconnection. Moreover, interconnection might occur within the system as well as between the system and environment. Thus, it is obvious that a complex system vision requires the understanding of different areas operating in different environments with multiple possible future solutions and consequences. Thus, Törnberg (2017) differentiates three levels of systems that engineers might encounter: complicated, complex, and wicked. According to his differentiation, complicated system comprises a lot of parts and interconnections; complex systems present the integration of physical and human world; wicked systems are very extended socio-technological systems without a definite description or even a goal because they are caused by many factors and require a unique solution.

Researchers attempted to find out the role of the psychological background of students for the systems thinking development. Frank (2010) designed CEST (capacity for engineering systems thinking) questionnaire that is based on the assessment of students interests and professional values. The test comprises 40 statements pairs distributed in accordance with the range of five factors: seeing the big picture, using interdisciplinary knowledge for conceptualising the solution, analysing the needs/requirements, being a systems thinker, implementing managerial considerations. In our opinion, the defined factors should be taken into consideration while creating a curricular as sub-skills of the mentioned above ability.

This idea evidences that fact that systems are not simple or single- compound phenomena. As reported by Barak (2018) systems thinking implicates analysing and awareness of a number of concepts, such as:

- Parts and structure of a system

- Factors that are important to an outcome

- The big picture or"macro view"

- System boundaries

- Function and behaviour

- Feedback in a system

- System dynamics

- Non-functional properties, such as safety and reliability, which arise from interactions between parts of a system (p.342)

The educator claims that "The examples of systems thinking in electronics demonstrate that teaching electronics could be an effective platform for fostering technological systems thinking, which is an essential factor in fostering design and problem-solving competences" (Barak, 2018, p. 342).

Surveys such as that conducted by Andreucci et al. (2012), have shown an opportunity of the system approach implementation through the STEAM integration. This implies that in order to develop students' awareness about systems, it is preferably to suggest this approach in different disciplines at the same time, because systems do not exist separately in the physical world and associated system thinking approaches students to real life. Technology education demonstrates a great capacity to diminish curricular fragmentation through the integration of interconnected disciplines content. This idea was proved with the releases of the Common Core State Standards for English Language Arts and Mathematics in the USA in 2010 (CCSS, 2010) which approve the integration of content and suggest designing interdisciplinary engineering curricular. Initially, this approach was introduced as STEM disciplines integration. However, education practitioners recommended adding arts with the sake of fostering creativity, innovation, literacy, communication and inventiveness (Daugherty, 2013). Moreover, Wilson-Lopez and Gregory (2015) outlined the synergy between engineering and literacy, as reading and writing instruction are considered to be crucial skills for modern engineers.

A great number of empirical education research and observations highlight that lecture-based singlediscipline engineering teaching does not promote critical and systemic thinking skills. Moreover, it is based 
on the deductive way of knowledge transition whereas STEAMapproach suggests inductive way due its systemic, creative and multidisciplinary character, and application of interactive methods (Connor et al., 2015). As we know, inductive way of teaching facilitates students' motivation to learn because new material is taught only after students feel the necessity to know it in order to fulfil a meaningful or interesting for them task.

Roberts (2012) states that integrated curricular are grounded on common traits: previously learnt principles from science, technology, engineering, art and mathematics allow students to apply information in a critical and creative way to find a solution to complex problems; STEAM approach is inquiry-based in nature that implies employing questioning techniques, empirical research and finding evidence-based solutions; development of soft skills (creativity, communication, critical thinking and collaboration).In favour of language art inclusion into this integration, we would like to refer the Bybee's (2010)research that reveals the necessity of teaching students language of technology because students should perceive, understand, analyse and produce field-related technology vocabulary to create collaboration networks and projects. This idea substantiates the application of content-based teaching since students are able to find examples of authentic technology discourse, language models, genres and structures only if specific contentbased resources, such as textbooks, manuals, articles, instructional videos etc.

Collectively, these studies outline a critical role of system thinking development for future engineers. And STEAM is considered as a possible solution to this challenge due to its integrative, individuallyfocused, adaptable and complex nature that simulates real-life situations. The following part of this paper moves on to describe in greater details the pedagogical strategies how to realise this approach with the stated goal in terms of pedagogically content knowledge framework.

\section{Research methodology}

Since our main research questions are of explanatory (how) and mediating nature (tools for improvement), we decided to carry out our research in the framework of the Design Research Methodology (Blessing and Chakrabarti, 2009) that is used for design engineering. This methodology reflects the process of our research and consists of four stages: Research Clarification, Descriptive Study I, Prescriptive Study, and Descriptive Study II. The research clarification stage allowed us to analyse the literature sources, textbooks, educational materials, find evidences and make assumption that led to the formulation of the research goals. The second stage is for the empirical data analysis, description of a current situation to find out what are the causes of the situation and what factors should be improved. The third stage prescriptive study deals with the verification and testing of initial assumptions and interventions. We suggested possible scenarios to influence the factors changes and tried to predict what solution or strategy would lead to the most efficient realisation of the research goal. Then we proceed to the descriptive study II where we were able to evaluate the usefulness, feasibility and conditions of the best scenario and interventions suggested in the previous stage.

\section{Data collection tools}

In the process of choosing the data collection tools, we outlined those which would provide us with answers to the research question. Thus, to support evidences, we used the following data collection methods: project journals, documentation review, interviews, observation, discussions with field experts, and problembased tests for skills level assessment. The project journal included participants' activities and classes' observation reflections, notes of informal talks with participants and their perception of the experimental activities. The journal was written chronologically during the entire process of the experiment and served as repository of the data. Documentation review included extra information to compare the data from the journal and planned steps and descriptions: specifications, lessons plans and reports, assessment results, curricular, students' tests, teachers' feedback. This tool provided us with external information about skills development dynamics through formal statistical and empirical data. We also carried out unstructured interviews with open-ended questions. The personal students' and teachers' opinion was important to understand the internal challenges and perspectives of the experiment. The data collection tools were correlated with four stages of the research methodology. Project journal was written during all four stages as well as observations; documentation review was performed during the research clarification and prescriptive stages; interviews were held during two last stages; discussions with field experts were during the first and last stages; level tests were carried out during the first and last stages.

The process of skills level tests design and performance requires some clarifications. As a research tool to assess the level of systems thinking, we took as an example Dimensions of Systems Thinking Framework developed by Grohs et al. (2018). The scenario-based framework comprises three dimensions for 
consideration - problem and its interrelation with perspective and time. The framework was created on the background of studying "problem-solving literature in engineering education, critical thinking literature in philosophy, as well as theory and scholarship related to leadership and community development, organisational studies, and public policy" (p. 6). Before and after the course, students were suggested a problem for a solution and they had to define the state of the problem, assess resources (current and additional), identify limitations and suggest possible solutions and predict consequences and perspectives, analyse past causes and future actions.

\section{Participants}

The research participants comprised two groups: teachers and students. We involved 25 bachelor students of the third course of the Department of Microelectronics of Faculty of Electronics, Igor Sikorsky Kyiv Polytechnic Institute because according to the syllabus they had the field-related subject "Physics of Dielectrics" and English language classes for electrical engineers. It implies that students could have the possibility to discuss the same topics during both courses and train systems thinking skills. We engaged teachers of the English course (3) and field-related course (1). Their participation was voluntary and they were provided with all necessary information about the experiment procedures, purposes and outcomes. Except for participants we had three internal observers and two external observers from other faculties.

\section{Research Procedure}

With the purpose to implement the above-stated approaches and examine the extent to which it is possible to develop systems thinking, we chose a physics of dielectrics course based on the textbook "Functional Dielectrics for Electronics. Fundamentals of conversional properties" (Poplavko and Yakymenko, 2020) that suggests an excellent opportunity to transform the electronics teaching into a model of real content-based STEAM approach implementation. The content of the textbook outlines the latest achievements in the field of dielectrics and introduces the contemporary tendency for mutual penetration and synthesis from different fields for material and curricular writing. The book is written in English to enhance students' filed-related language skills, and presents mathematical treatment of theories with emphasis on the basic concepts of physical phenomena in materials and main physical processes that provide the electrical, mechanoelectrical, thermoelectrical, and other conversion phenomena in polar crystals. Most chapters are devoted to the advanced scientific and technological problems of electronic materials and functional dielectrics.

The 6-week STEAM integrated course was conducted with one separate group of students $(n=25)$ who studied dielectrics in English. On the first class, students performed the problem-based test for systems thinking skills assessment, then they had 10 integrated classes on dielectrics with inclusion of STEAM integrated subjects and educational strategies aimed at the systems thinking skills development. At the last class students again performed the problem-based test for systems thinking skills assessment the same in form but different in content.

\section{Research ethics}

The data collection has been performed according to general standards of research ethics as recommended by the Academy of Pedagogical Science and was approved by the Research Board of the Faculty of Linguistics. The observers' team included teachers from both faculties who did not conduct classes either participated in the research themselves to keep the objectivity of the process and results. Before the experiment started, participants were informed about the nature of experiment, the confidentiality of the observation data, their right to familiarise with the experiment results and were asked for their permission to publish the results of the experiment. Students could stop the participation at any time without any academic consequences. It was emphasised that results did not deal with individual abilities assessment and data would not influence the academic performance.

\section{Results}

The main goal of our research was to find tools that might improve the systems thinking while conducting the integrated course. So, first, we had to measure the level of present systems thinking. Thus, taking as a background the Dimensions of Systems Thinking Framework (Grohs et al., 2018), we developed the rubrics for assessment the systems thinking skills. We added some points for the assessment as in our opinion these points are critical for the successful solution for technical problems. The level of systems thinking was measured for all dimensions using 5 point scale where 1 is poor and 5 is an excellent solution. 
Table 1 demonstrates the results of the tests, we calculated the average grade for each sub-dimension for 25 students.

\begin{tabular}{|c|c|c|}
\hline Dimension & Initial test & Final test \\
\hline \multicolumn{3}{|l|}{ Problem: } \\
\hline Problem identification & 4.04 & 4.7 \\
\hline Goal identification & 4.02 & 4.5 \\
\hline Information needs identification & 3.05 & 4 \\
\hline Resources/tools identification and assessment & 3 & 3.8 \\
\hline Stakeholders identification & 2.4 & 3 \\
\hline \multicolumn{3}{|l|}{ Perspective: } \\
\hline Feasibility of possible solutions & 2.6 & 3.4 \\
\hline Challenges/ barriers & 3.3 & 4 \\
\hline Sustainability of the solution & 3 & 3.8 \\
\hline Preventive measures & 3.8 & 4.4 \\
\hline \multicolumn{3}{|l|}{ Time: } \\
\hline Causes identification & 3.7 & 4.3 \\
\hline Time framework identification for the solution & 3.3 & 4 \\
\hline Short and long term effects & 3.6 & 4.2 \\
\hline
\end{tabular}

Next 8 weeks we observed STEAM integrated classes with a view of finding out what tools are used for the development of system thinking and what components of the STEAM course are mostly impacted. Having analysed the literature on system thinking tools methods (Rashmi, Sheppard, Mcgrath, and Gallois, 2009, Awad and Barak, 2014), we chose the list and suggested teachers some tools and teachers empirically tested them at classes and informed us about the most useful ones. We noticed that despite the course integrated main components math, physics, engineering technologies and English language (Art) that were joined by the same topic, pedagogical approach and methods, however, teachers used different systems thinking development tools. Table 2 demonstrates the comparison of applied methods and tools.

Table 2. System thinking teaching methods

\begin{tabular}{|l|l|}
\hline Science and technology disciplines & Art (English language ) \\
\hline Systems dynamic modelling & Systems dynamic mapping \\
\hline Assumption-based planning & Outcome mapping \\
\hline Causal loop diagrams & E-books writing \\
\hline Influence Diagrams & Persuasive writing essays \\
\hline Root cause analysis & \\
\hline Feedback loops analysis & \\
\hline Behaviour over time diagrams & \\
\hline
\end{tabular}

\section{Discussion}

It is well-recognised that modern technology is impossible without electronics, therefore, students have been taught electronics since the development of the first engineering system. And as any long-termed process, it requires revision and reformations to be relevant to modern technological and educational changes as well. The first challenge is to teach students systems and systems thinking to provide the holistic and authentic concept of teaching. The second necessary reform is about designing an interdisciplinary curricular in terms of STEAM approach that enhances different types of individual system thinking providing systemic attitude to the curricular development. The third change deals with advanced and interactive pedagogical forms and methods of teaching as content-based instruction and problem-based learning.

The key idea of system thinking is to be able to see the "whole" and to understand the interrelations between the system and its compounds in terms of past, present and future time frame. There is no a single machine or device that is not a system itself. And the designing of this system requires the collaboration of specialists of different engineering profiles. Therefore, skills of system thinking and understanding of integration principles as well as collaboration are vital for today's engineers. In electronics, systems thinking means teaching students to understand the interconnection of the compounds and to assess its output; to see one system as a part of another larger system and follow their interconnection bonds. Problem solving is seen as a tool for system thinking application by means of which students realise the importance of 
interconnectedness and dependence of sub-systems in a technical world. The most efficient ways to teach system thinking in technology education are interdisciplinary, individually-focused STEAM approach, implementation of problem-based learning and content-based instruction.

An intradisciplinary curriculum design implies collaborative participation of teachers from different disciplines to correlate the goals, forms and outcomes of the teaching. It is worth mentioning the differentiation between levels of STEAM subject integration (English, 2016):

- Multidisciplinary-common topic is taught separately in each discipline;

- Interdisciplinary-interconnected concepts are taught from two or more disciplines with the common aim;

- Transdisciplinary-application of acquired knowledge and skills to real-world problems solutions or projects.

In the present case, we are dealing with the interdisciplinarity because we are describing the experience of in-class form and methods of integrated electronic teaching to set the background necessary for transdisciplinary practical knowledge application. With this in mind, we recognise electronics as an efficient scaffold for illustrating the opportunities and outcomes of STEAM approach implementation. It is wellknown that electronics is based on physics knowledge, mathematics logarithms and functions awareness as well as principles of the science nature for analysing the systems design, feasibility, safety, efficiency and sustainability. Moreover, every electronic engineer should know the basics of control systems or electronic circuits performance which is impossible without math or physics comprehension.

An initial objective of the project was to identify the educational strategies for systems thinking development in terms of STEAM approach. Prior studies defined four content features of systems thinking: components, context, relationships, and dynamics of a system-of-interest (Hubert,2014). It is obvious that a system has components and relationship between them, however, not all systems are dynamic. In case of electronics teaching, we deal with two dynamic systems: electronics and pedagogy, that are constantly developing and transforming. Haskins et al. (2010), claim that systems thinking "occurs through discovery, learning, diagnosis, and dialogue" (p. 7) and we consider that this statement defines the nature of educational strategies which should be applied for the systems thinking development. By implementing systems thinking, learners relate new knowledge to their previous knowledge and experience. According to Davidz and Nightingale (2008), the key factors that facilitate systems thinking development are: experiential learning, a supporting students-centred environment, curiosity, inquiry-based learning, communication, tolerance for uncertainty, and thinking out of the box. All these abilities can be developed through STEAM approach integrated into technical education: all engineering teaching is experiential and inquiry-based, to solve problems students should think out of the box, ask questions and use extend knowledge from all disciplines they were taught. The implementation of mentioned techniques is impossible in not student-centred environment and without perception of individual students features.

Systems thinking tools and methods serve a specific purpose and require a particular educational procedure for implementation. Having observed classes with employing some of systems thinking tools and having interviewed teachers afterwards, we identified the most efficient and stimulating ones. First, we would like to analyse those tools that were used during field-related classes, particular on physics of dielectrics.

1. Systems dynamic modelling is the most widely used techniques as the electronics is a dynamic system itself so it cannot be taught without systemic modelling.

2. Causal loop diagrams expose the interrelation of variables in a system. This tool helps demonstrate how one variable can affect another variable to change the whole system. When showing the relationship between parts of a system casual network can be marked as the "similar" or "opposite" characteristics to demonstrate more precisely how arts influence each other. In fact, mostly all physical processes are causal loops since we can trace transformations of the processes happening during a definite period of time as relaxation or resonance.

3. Influence diagrams are specifically focused on analysing the impact of system components with a prediction of possible consequences in case of losing or adding an element.

4. Feedback loop analysis visualises the influence of input to output and vice versa. For example, dielectric properties can be explained by a double-well potential model with fluctuating charges. The temperature, as well as the local field at the double wells, influence the changes rate of charges. Knowing the effect of the transition rates of the dipoles and the local field, students are able to see the feedback loop of polarisation (Leschhorn and Kliem, 2016, Poplavko and Yakymenko, 2020).

5. Root causes analysis prevents superficial problems solutions. It involves skills of thinking inside the box when students explore the initial deep causes of systems changes and can easily explain why some solutions will work or will not work. 
6. Behaviour-over-time diagrams are similar to causal loops but more focused on time variables affecting the work of the system.

The following methods were used mostly by language teachers as they contribute to the language competences development. These methods were supplementary to the main teaching process that happened at the classes of physics of dielectrics and were connected with topic and outcome to develop system thinking but through the language.

1. Mapping systems, as well as outcome mapping, were used to teach students to identify parts of the system and their interaction or outcomes. It was mostly used by language teachers as this method allows students to think of words or metaphors they associate with a system, phrases or whole definitions. Teachers can change the focus of mapping, so it might be exact details, functions, interconnections or even stakeholders involvement.

2. Writing e-books develops students' capacity to identify systems' parts and describe steps how to fix, upgrade, operate or adjust the system to necessary conditions.

3. Persuasive debating requires skills of systems thinking because in the process of persuasion students had to demonstrate a deep understanding of causes and perspectives of the system to prove its efficiency or sustainability. When students attempt to convince that their suggestion or improvement is the best, they find new connections between parts and new capabilities of a system.

The results displayed in Table 1 confirm the efficiency of these strategies application comparing the initial and final tests scores. Among the skills that were changed the most we identified: information needs and general resources identification, feasibility and sustainability of solution assessment, root causes identification and perspectives evaluation. Before the experiment, students were able to identify a problem and suggest a superficial solution, mainly by changing one variable of the problem. However, after the experiment, students understood the nature of the holistic approach to the problem solution.

An example of such STEAM integrated class, we can describe an approximate plan of class connected with physics of dielectrics we tried to perform during our experiment. Students are asked to solve a problem, by reading a textbook (English language arts) "Functional Dielectrics for Electronics. Fundamentals of conversional properties"(Poplavko and Yakymenko, 2020) where they find out new information, then students can make graphical schemes, scales or models of a system or a phenomenon (drawing, math), find evidence how this system works, analyse properties, find connections, calculate its efficiency and performance coefficient (science), explore technologies to produce or reinforce the system (technology) and the last activity that can be performed at English classes as a continuation of previous activities is a persuasive writing or debating on why this phenomenon is important or can be upgraded.

As our finding evidence, we support the idea expressed by Goodman (1991) system thinking skills can also be used to enhance language learning. Language classes also employ a lot of schemes and diagrams, for example, a conditional sentence structure can be seen as a causal loop where key variables are linked and influence each other, moreover, some loops can be seen as a text. Another example is the text analysing: students find keywords or grammar patterns, trace out main arguments and evidences that scaffold the structure of a discourse.

It is worth mentioning that the key principle of systems thinking is an interconnectedness that can be provided by integrative educational environment such as STEAM. It equips students with a dynamic, interrelated, holistic specialism attitude and feedback loops. By employing these new skills students change their problem perception completely. Thus, they do not isolate components of the problem to understand its nature; problems solutions are analysed depending on causes and perspectives; all factors and components connected to a problem are taken into account; to find the best solution students investigate feedback; the process of the problem solution turns from linear to broad-minded accepting all possible processes and factors. But the key idea of this thinking transformation is that students understand that if they improve one part of the system it might results in wrong solution in long-termed perspective. Only through remodelling and upgrading the relationships between all parts the whole system work can be improved. And all these changes are possible with STEAM approach integration into the technical education.

\section{Limitations}

Although the results of the experiment demonstrated the improvement of system thinking skills, this study does not provide a complete picture of the process. Firstly, the study was limited by the absence of variety in engineering disciplines students are taught. Secondly, it would be better to develop a differentiated assessment rubrics by levels: low, medium and high level. 


\section{Conclusions}

In summary, electronics, as well as technical education in general, provides a flexible and rich learning environment that can be reinforced with STEAM approach. Through such transformations, we are able not only develop technological literacy but fostering cognitive skills such as creative, critical and systems thinking for problem-solving process. Our research confirms the hypnosis that integrative educational environment contributes to the development of systems thinking skills and it can be performed both during field-related disciplines and humanities.

\section{References}

Andreucci, C., Chatoney, M., \& Ginestie, J. (2012). The systemic approach to technological education: Effects of transferred learning in resolving a physics problem. International Journal of Technology and Design Education, 22(3), 281-296. https://doi.org/10.1007/s10798-010-9148-y

Awad, N. \& Barak, M. (2014). Sound, waves and communication: Students' achievements and motivation in learning a STEMoriented program. Creative Education, 5(23), 1959-1968. https://doi.org/10.4236/ce.2014.523220

Barak, M. (2018) Teaching Electronics: From Building Circuits to Systems Thinking and Programming in M. J. de Vries (ed.), Handbook of Technology Education (pp. 337-360). Dordrecht, Netherlands: Springer. https://doi.org/10.1007/978-3-319-44687-5_29

Barlex, D. \& Steeg, T. (2007). Developing engineers; The case of electronics education in English schools. IEEE International Summit "Meeting the growing demand for engineers and their educators 2010-2020" (pp.9-11). Munich. https://doi.org/10.1109/mgdete.2007.4760345

Blessing, L. \& Chakrabarti, A. (2009). DRM, a Design Research Methodology. Springer. https://doi.org/10.1007/978-1-84882-587-1

Bybee, R. W. (2010). Advancing STEM education: A 2020 vision. Technology and Engineering Teacher, 70, 30-35. Retrieved from https://eric.ed.gov/?id=EJ898909

Common core state standards for English Language Arts (2016). National Governors Association Center for Best Practices \& the Council of Chief State School. Retrieved from /CCSSI_ELA\%20Standards.pdf

Connor, A., Karmokar, S., \& Whittington, C.(2015). From STEM to STEAM: Strategies for Enhancing Engineering \& Technology Education. International journal of engineering pedagogy, 5(2), 37- 47. http://dx.doi.org/10.3991/ijep.v5i2.4458

Davidz, H.L., \& Nightingale, D.J. (2008). Enabling systems thinking to accelerate the development of senior systems engineers. INCOSE Journal of Systems Engineering, 11(1), 1-14. https://doi.org/10.1002/sys.20081

Daugherty, M. K. (2013). The prospect of an "A" in STEM. Journal of STEM Education, 14(2), 10-15. Retrieved from http://www.uastem.com/

English, L. D. (2016). STEM education K-12: Perspectives on integration. International Journal of Stem Education, 3(1), 1-8. https://doi.org/10.1186/s40594-016-0036-1

Frank, M. (2012). Engineering Systems Thinking: Cognitive Competencies of Successful Systems Engineers. Procedia Computer Science, 8, 273-278. https://doi.org/10.1016/j.procs.2012.01.057

Frank, M. (2010). Assessing the interest for systems engineering positions and other engineering positions' required capacity for engineering systems thinking (CEST). Systems Engineering, 13(2), 187-195. https://doi.org/10.1002/sys.20140

Frank, M. \& Elata, D. (2005). Developing the capacity for engineering systems thinking (CEST) of freshman engineering students. Systems engineering, 8(2), 187-195. https://doi.org/10.1002/sys.20025

Foster, C., Florhaug, J. A., Franklin, J., Gottschall, L., Hrovatin, L. A., Parker, S., et al. (2001). A new approach to monitoring exercise training. Journal of Strength and Conditioning Research, 15(1), 109-115. https://doi.org/10.1519/00124278200102000-00019

Goodman, M. (1991). Systems thinking as a language. The Systems thinker, 2(3). Retrieved from https://www.appliedsystemsthinking.com/supporting_documents/IntroLanguage.pdf

Haskins, C., Forsberg, K., Krueger, M., Walden, D., \& Hamelin, R.D. (2010). INCOSE Systems Engineering Handbook : A guide for system life cycle processes and activities. San Diego, CA.

Grohs, J., Kirk, G., Soledad, M., \& Knight, D. (2018). Assessing Systems Thinking: A Tool to Measure Complex Reasoning through Ill-Structured Problems.Thinking Skills and Creativity, 28, 110-130. https://doi.org/10.1016/j.tsc.2018.03.003

Hubert, A. (2014). Systems Engineering, Systems Thinking, and Learning.Springer.

Leschhorn, A. \& Kliem, H. (2016). A feedback model for dielectrics, ferroelectrics and relaxors. IEEE Conference on Electrical Insulation and Dielectric Phenomena (CEIDP) (pp.89-92). Toronto. https://doi.org/10.1109/CEIDP.2016.7785505

Poplavko,Y. \& Yakymenko, Y. (2020). Functional Dielectrics for Electronics. Fundamentals of conversional properties. Woodhead Publishing

Rashmi, J., Sheppard, K., Mcgrath, E., \& Gallois, B. (2009). Promoting Systems Thinking in Engineering and Pre-Engineering Students. American Society for Engineering Education Conference Proceedings, Best Paper Award. Retrieved from https://www.asee.org/papers-and-publications/papers/section-proceedings/middle-atlantic/spring-2008

Roberts, A. (2012). A justification for STEM education. Technology and engineering teacher. Retrieved from https://www.semanticscholar.org/paper/A-Justification-for-STEM-EducationRoberts/b8cd48a3044ee1e7dcc7b734a8f5cab1042b6eac

Törnberg, P. (2017). Worse than Complex. Doctoral dissertation, Chalmers University of Technology. Göteborg, Sweden. Retrieved from http://publications.lib.chalmers.se/records/fulltext/247725/247725.pdf

Wilson-Lopez, A. \& Gregory, S. (2015). Integrating literacy and engineering instruction for young learners. The Reading Teacher, 69(1), 25-33. https://doi.org/10.1002/trtr.1351 